\title{
Unknown Oral Contraceptive Use
}

National Cancer Institute

\section{Source}

National Cancer Institute. Unknown Oral Contraceptive Use. NCI Thesaurus. Code C159773.

An individual whose use of oral contraceptives is unknown. 